\title{
EFEITO DO ESPAÇAMENTO E DO USO DE LEGUMINOSAS DE COBERTURA NO MANEJO DE PLANTAS INVASORAS EM REFLORESTAMENTO DE Schizolobium amazonicum HUBER EX. DUCKE (PARICÁ) ${ }^{1}$
}

\author{
Fabrízia de Oliveira Alvino-Rayol², Leonilde dos Santos Rosa ${ }^{3}$ e Breno Pinto Rayol ${ }^{4}$
}

\begin{abstract}
RESUMO - A infestação crescente de plantas invasoras em áreas de cultivos é um dos fatores que mais afetam os reflorestamentos na Amazônia, causando decréscimos na produtividade devido à competição direta pelos fatores de produção. Tendo isso em vista, este trabalho objetivou avaliar o efeito de espaçamentos (4x2 m, $4 \times 4 \mathrm{~m}$ e 4x6 m) e do uso de leguminosas de cobertura (Cajanus cajan e Canavalia ensiformis) no controle da matocompetição em plantio de Schizolobium amazonicum Huber ex. Ducke (paricá). As coletas das plantas invasoras foram feitas aos 30 e 90 dias após a semeadura das leguminosas de cobertura. Posteriormente foram levadas para herbários para identificação. Foram identificadas 24 espécies distribuídas em 13 famílias botânicas. No que se refere à infestação, diversidade e riqueza de plantas daninhas, os melhores resultados foram encontrados nos tratamentos com C. ensiformis. Esta leguminosa influenciou a composição florística e a estrutura das comunidades de plantas invasoras. O espaçamento $4 \mathrm{~m}$ x $2 \mathrm{~m}$ contribuiu para menor diversidade e riqueza dessa plantas. As espécies de ervas daninhas mais frequentes em todos os tratamentos foram Spermacoce capitata e Brachiaria brizantha.
\end{abstract}

Palavras-chaves: Schizolobium amazonicum, Plantas invasoras, Controle e Amazônia.

\section{EFFECT OF SPACING AND OF THE USE OF COVER LEGUMES IN THE MANAGEMENT OF WEED IN Schizolobium amazonicum HUBER EX. DUCKE PLANTATION}

\begin{abstract}
The increasing infestation of invading plants in cropping areas is one of the factors that affect most reforestation in Amazon, causing decreases in productivity due to direct competition for production factors. The objective of this study was to evaluate spacing effect $(4 \times 2 \mathrm{~m}, 4 \times 4 \mathrm{~m}$ and $4 \times 6 \mathrm{~m})$ and the use of cover legumes (Cajanus cajan and Canavalia ensiformis) in the control of weed competition in Schizolobium amazonicum Huber ex. Ducke (Paricá) planting. The collections of invading plants were made 30 and 90 days after cover legumes sowing. Afterwards, they were taken to herbaria for identification. It was identified 24 species distributed in 13 botanical families. Regarding the infestation, diversity and richness of weeds, the best results were found in treatments with C. Ensiformis. This legume influenced the floristic composition and structure of communities of invading plants. The use of $4 m \times 2 m$ spacing contributed to less diversity and richness of those plants. The species of weeds most frequent in all treatments were Spermacoce capitata and Brachiaria brizantha.
\end{abstract}

Key-words: Amazon, Control, Schizolobium amazonicum and Weed.

\footnotetext{
${ }^{1}$ Recebido em 21.01.2009 e aceito para publicação em 14.04.2011.

${ }^{2}$ Instituto Federal de Educação Ciência e Tecnologia do Pará, IFPA, Brasil. E-mail: <fabriziaalvino@yahoo.com.br>.

${ }^{3}$ Universidade Federal Rural da Amazônia, UFRA, Brasil. E-mail: <leonilders@yahoo.com.br>.

${ }^{4}$ Universidade Federal do Oeste do Pará, UFOPA, Brasil. E-mail: <bprayol@yahoo.com.br>.
} 


\section{INTRODUÇÃO}

A possibilidade de efetuar cultivos na maioria dos solos de terra firme na Amazônia esbarra em problemas como a baixa fertilidade do solo e a alta incidência de plantas invasoras, as quais são menos exigentes e mais adaptadas às condições adversas de reduzida reserva de nutrientes no solo, razão do sucesso da sua proliferação (DIAS-FILHO, 1990).

A alta capacidade de adaptação das espécies de plantas daninhas aos diferentes ambientes favorece o estabelecimento da competição com as espécies de valor econômico pelos fatores que afetam a produção (água, nutrientes e radiação solar). Como consequência, essa competição causa desequilíbrio, provocando decréscimos acentuados na produtividade, quer pelos compostos alelopáticos liberados, quer pela competição direta pelos fatores mencionados (CARVALHO;TORRES, 1994). As plantas daninhas servem de hospedeiras a diversas espécies de insetos e doenças, além de criar condições favoráveis à procriação de roedores (ANDRADE; RAMALHO, 1997).

Para reduzir esses problemas, torna-se necessário adotar práticas que diminuam a competição provocada por plantas invasoras que tornem o ambiente favorável à cultura de interesse econômico. Uma das práticas para o controle da matocompetição é o uso de leguminosas de cobertura, que, além de apresentar benefícios em termos de conservação do solo, cria condições semelhantes às das comunidades naturais no que tange à permanência de resíduos no solo e à diversificação de espécies (LOPES, 2000).

O estudo das leguminosas tem demonstrado grande potencial na proteção e na recuperação da produtividade do solo (LOPES, 2000). Todavia, devem ser estabelecidos esquemas de uso compatíveis com as diferentes espécies florestais e com os sistemas de produção, bem como levar em consideração o clima e o solo específicos de cada região, além da demanda de insumos externos.

Aliado a este aspecto, o emprego de leguminosas de cobertura, além de apresentar um enorme potencial de reabilitação de áreas degradadas, visa à conservação e melhoria da fertilidade e ao incremento da produtividade das espécies de valor econômico, madeireiras, agrícolas ou produtoras de grãos.

Revista Árvore, Viçosa-MG, v.35, n.3, p.391-399, 2011
Em relação à seleção de leguminosas utilizadas para cobertura, foram considerados aspectos relacionados à rusticidade quanto às condições edafoclimáticas; à resistência ao ataque de pragas e doenças; à potencialização da conservação; ao fornecimento de adubação verde; ao aproveitamento dos grãos para comercialização; e ao desempenho satisfatório quanto à cobertura do solo e supressão de invasoras.

As leguminosas selecionadas foram: Canavalia ensiformis (feijão-de-porco), planta herbácea pertencente à família Mimosaceae, de porte ereto e hábito de crescimento determinado, de $0,60 \mathrm{~m}$ a $1,2 \mathrm{~m}$ de altura (LOPES, 2000). O crescimento inicial do feijão-de-porco é rápido, apresentando controle eficiente sobre as invasoras. Outra característica importante desta espécie é a capacidade de regeneração de biomassa aérea após o manejo (LOPES, 1998); Cajanus cajan (feijão-guandu), uma planta arbustiva, semiperene, pertencente à família Mimosaceae, com hábito de crescimento determinado, de 1,5 a 4,0 m de altura. É encontrada com frequência na maior parte do Brasil, podendo ser observada nos quintais da maioria das cidades. Esta popularidade deriva do fato de seus grãos verdes serem muito palatáveis, podendo substituir ervilhas; seus grãos secos podem ser empregados da mesma forma que o feijão para o consumo humano (EMBRAPA, 2004).

A adoção de espaçamentos menores entre culturas de interesse é outra prática que pode minimizar a matocompetição, em decorrência do rápido fechamento do dossel, do sombreamento e da rápida cobertura dos espaços vazios nas áreas de cultivo, diminuindo, por conseguinte, a matocompetição.

Desse modo, este trabalho teve como objetivo avaliar o efeito do espaçamento e do uso de leguminosas de cobertura da espécie Cajanus cajan (feijão-guandu) e Canavalia ensiformis (feijão-de-porco) no manejo da matocompetição em plantio de Schizolobium amazonicum (paricá), cultivado em diferentes espaçamentos.

\section{MATERIAL E MÉTODOS}

Esta pesquisa foi realizada em área de pastagem degradada pertencente à empresa PAMPA EXPORTAÇÕES LTDA, localizada no Município de Vigia, distante $35 \mathrm{~km}$ da Rodovia PA-140, nordeste do Estado do Pará ( $00^{\circ} 51^{\prime} 12^{\prime \prime}$ de latitude sul e $48^{\circ} 08^{\prime}$ 41 de longitude oeste). 
A área foi roçada e preparada mecanicamente. As covas para o plantio do paricá foram abertas com auxílio de coveador mecânico. A fertilização foi realizada durante a fase de pré-plantio, utilizando-se adubo orgânico (esterco de ave) e químico (NPK-18:18:18) nas proporções de $6 \mathrm{~L} \mathrm{cova}^{-1}$ e $150 \mathrm{~g} \mathrm{cova}^{-1}$, respectivamente.

O delineamento estatístico adotado para o experimento foi blocos ao acaso, com três repetições e sete tratamentos. Os tratamentos resultaram da combinação de três espaçamentos do paricá (4x2 m, $4 \times 4 \mathrm{me} 4 \times 6 \mathrm{~m}$ ), associados à presença de duas leguminosas de cobertura Cajanus cajan (feijão-guandu) e Canavalia ensiformis (feijão-de-porco). Os tratamentos testados foram os seguintes:

Tratamento 1: Schizolobium amazonicum $(4 \mathrm{mx} 2 \mathrm{~m})$
com C. cajan

Tratamento 2: S. amazonicum ( $4 \mathrm{~m} \times 2 \mathrm{~m})$ com $C$. ensiformis

Tratamento 3: S. amazonicum (4m x 4m) com C. cajan

Tratamento 4: S. amazonicum $(4 \mathrm{~m} \times 4 \mathrm{~m})$ com $C$. ensiformis

Tratamento 5: S. amazonicum (4m x 6m) com C. cajan

Tratamento 6: S. amazonicum $(4 \mathrm{~m} \times 6 \mathrm{~m})$ com $C$. ensiformis

Tratamento 7: S. amazonicum (4m x 4m) em monocultivo

A área total de cada bloco foi $4032 \mathrm{~m}^{2}$. A distância entre parcelas e blocos foi de $3 \mathrm{~m}$, totalizando assim uma área experimental de 1,45 ha. O paricá foi semeado diretamente no campo no início do período chuvoso, em janeiro de 2004, obtendo índice de germinação de $90 \%$, e as plantas com altura média de $2 \mathrm{~m}$ aos quatro meses de idade, obtendo ertasantio do parica (onados, belecimento da competiç. A semeadura das leguminosas de cobertura (feijão-de-porco e feijão-guandu) foi realizada diretamente entre as plantas de paricá com auxílio de plantadeira manual, no final de maio de 2004, período adequado para a semeadura dessas sementes, ambas nos espaçamentos de $0,5 \mathrm{~m}$ x 0,5m.

O estudo da composição florística foi realizado aos 30 e 90 dias após a semeadura das leguminosas, adotando o seguinte procedimento: a) foram consideradas invasoras todas as plantas que se encontravam nas parcelas e que não eram S. amazonicum e tampouco leguminosas de cobertura C. cajan ou C. ensiformis; b) para os indivíduos amostrados foi coletado o material botânico para identificação taxonômica, através de comparações com exsicatas depositadas nos herbários localizados em Belém-PA; c) a identificação foi feita por família, seguida da identificação das espécies. As amostras de material botânico não identificadas nos herbários receberam códigos de morfotipo e foram consideradas como espécies diferentes entre si.

A infestação de ervas daninhas foi avaliada utilizando-se um quadrado de madeira com dimensões de $0,5 \mathrm{~m} \times 0,5 \mathrm{~m}\left(0,25 \mathrm{~m}^{2}\right)$, que foi atirado ao acaso cinco vezes em cada parcela, totalizando $1,25 \mathrm{~m}^{2}$. Aos 30 e 90 dias após a semeadura das leguminosas de cobertura, foi estimada, ao acaso, em cada parcela, a porcentagem de cobertura vegetal de cada espécie de leguminosas de cobertura e de solo exposto.

Para o cálculo da porcentagem de infestação das plantas invasoras, utilizou-se a seguinte fórmula: $I \%=100 \%-S E \%-L C \%$, em que $\mathrm{I} \%=$ porcentagem de infestação das plantas daninhas em cada parcela; $\mathrm{SE} \%$ = porcentagem de solo exposto em cada parcela; LC \%= porcentagem de leguminosas de cobertura.

A riqueza, definida como número de espécies presentes em determinada área, foi estimada por meio da contagem das espécies de ervas daninhas que ocorreram em cada tratamento. Adiversidade de espécies nos diferentes tratamentos, por sua vez, foi calculada pelo índice de diversidade de Shannon-Weaver ( $\left.\mathrm{H}^{\prime}\right)$. Esse índice foi calculado segundo Ludwig e Reynolds (1988), como segue: $p i=\frac{n i}{N} \quad H^{\prime}=-p i \cdot \ln p i$ sendo PI a razão do número de indivíduos por espécie pelo número total de indivíduos amostrados; ni o número de indivíduos da espécie i; N o número total de indivíduos amostrados.

A estrutura horizontal da área experimental foi avaliada através dos seguintes parâmetros: densidade relativa, frequência relativa, dominância relativa e Índice de Valor de Importância das ervas daninhas. Esses parâmetros foram determinados por meio das seguintes fórmulas, as quais foram empregadas por MullerDombois e Ellenberg (1974):

a) Densidade Relativa (DR), expressa em porcentagem conforme a equação:

$$
D R=\left(\frac{D A i}{\sum D A i}\right) 100
$$

Revista Árvore, Viçosa-MG, v.35, n.3, p.391-399, 2011 
sendo DAi = densidade absoluta de uma espécie i

$\sum \mathrm{DAi}=$ densidade total das espécies

b) Frequência Relativa (FR), calculada através da seguinte equação:

$$
F R=\left(\frac{F A i}{\sum F A i}\right) 100
$$

em que $\mathrm{FAi}$ = frequência absoluta de uma espécie $\mathrm{i}$

$$
\sum \text { Fai }=\text { frequência total das espécies }
$$

c) Dominância Relativa (DoR), expressa pela equação:

$$
D o R=\left(\frac{D o A}{\sum D o A}\right) 100,
$$

em que DoA = dominância absoluta de uma espécie i

$\sum$ DoA = dominância total das espécies;

d) O Índice de Valor de Importância (IVI) foi obtido por meio da soma da densidade relativa, frequência relativa e dominância relativa.

Os dados referentes à porcentagem de infestação das plantas invasoras, bem como o Índice de diversidade de Shannon-Weaver, foram submetidos à análise de variância, e as médias foram comparadas pelo teste de Tukey a 5\% de probabilidade de erro. Para isso, utilizou-se o programa Bio Estat 3.0 (AYRES et al., 2003).

\section{RESULTADOS}

O inventário da composição florística realizado aos 30 dias após a semeadura das leguminosas revelou a ocorrência de plantas pertencentes a dez famílias botânicas, 17 gêneros e 17 espécies na área experimental (1,76 ha). Cabe mencionar que não foi possível identificar taxonomicamente todas as espécies amostradas, pois parte do material coletado não apresentava estruturas reprodutivas necessárias para a identificação.

As famílias Poaceae e Euphorbiaceae apresentaram maior número de espécies, com quatro e três espécies, respectivamente; as famílias Cyperaceae e Solanaceae apresentaram duas espécies apenas. Das famílias Convolvulaceae, Asteraceae, Cucurbitaceae, Fabaceae, Bignoniaceae e Rubiaceae, foi identificada somente uma espécie de cada (Tabela 1).

Na avaliação realizada aos 90 dias após a semeadura das leguminosas de cobertura, foram registradas 14 espécies, distribuídas em nove famílias botânicas, e 13 gêneros. Das famílias botânicas identificadas, as que apresentaram maior número de espécies foram:
Poaceae (três), Bignoniaceae (duas) e Lecytidaceae (duas), e as demais famílias apresentaram uma única espécie (Tabela 1).

Os dados referentes à infestação, à diversidade e à riqueza de ervas daninhas nos diferentes tratamentos, aos 30 e 90 dias, são apresentados na Tabela 2. Verifica-se que, após 30 dias de semeadura das leguminosas, o tratamento T2 (4m x 2m com feijão-de-porco) registrou o menor índice de infestação. No que se refere à variável diversidade, nota-se que, aos 30 dias, a diversidade de espécies invasoras verificada nos tratamentos T5 (4m x 6m - feijão-guandu) e no de paricá em monocultivo (4m x 4m) não diferiram entre si (Tabela 2).

Os resultados da densidade, frequência, dominância relativa e índice de valor de importância de cada tratamento na primeira medição podem ser observados na Tabela 3. As espécies da família Poaceae, como Brachiaria brizantha e Digitaria ciliares, apresentaram maior densidade relativa, frequência relativa e dominância relativa, quando comparadas às demais espécies. Por outro lado, Cucumis anguria, Solanum juripeba, Memora allamandiflora, Phyllanthus niruri e Stryphnodendron pulcherrimum, quando comparadas às demais espécies coletadas, apresentaram os menores valores de densidade relativa, frequência relativa e dominância relativa. A espécie $B$. pilosa também apresentou valores relativos baixos de densidade, frequência e dominância.

Tratando-se da dominância relativa, nota-se, na Tabela 3, que as espécies Brachiaria brizantha e Digitaria ciliaris, ambas da família Poaceae, juntas, perfazem até $41,73 \%$ da cobertura total da comunidade invasora.

Com relação ao índice de valor de importância (IVI), observa-se, na Tabela 3, que houve variação de 1,27\% a 74,63\% entre as espécies. Brachiaria brizantha foi a espécie que registrou maior IVI, devido à grande abundância e dominância de sua população. Outras espécies, como Digitaria ciliaris, Fimbristylis dichotoma, Spermacoce verticillata, Ipomea sp., também apresentaram valores significativos de IVI. As demais espécies apresentaram IVI inferiores a 10\%.

No que diz respeito à frequência relativa, as espécies Spermacoce capitata e Brachiaria brizantha apresentaram os maiores valores em percentagem.

No que tange à dominância relativa, nota-se, na Tabela 3, que as espécies Spermacoce capitata, Eragrostis ciliaris e Brachiaria brizantha 
Tabela 1 - Listagem das famílias e espécies de plantas daninhas amostradas aos 30 e 90 dias após a semeadura das leguminosas de cobertura em um plantio de Schizolobium amazonicum.

Table 1- List of families and species of weeds sampled 30 and 90 days after sowing of cover legumes on a Schizolobium amazonicum plantation.

\begin{tabular}{|c|c|c|c|}
\hline Família & Espécie & 30 Dias & 90 Dias \\
\hline ASTERACEAE & $\begin{array}{l}\text { Bidens pilosa L. } \\
\text { Conyza sp. }\end{array}$ & $\begin{array}{l}\mathrm{O} \\
-\end{array}$ & $\overline{\mathrm{O}}$ \\
\hline$\overline{\text { BIGNONIACEAE }}$ & $\begin{array}{l}\text { Memora allamandiflora } \\
\text { Memora magnifica }\end{array}$ & $\begin{array}{l}\mathrm{O} \\
-\end{array}$ & $\begin{array}{l}\mathrm{O} \\
\mathrm{O}\end{array}$ \\
\hline CONVOLVULACEAE & Ipomoea sp. & $\mathrm{O}$ & - \\
\hline CUCURBITACEAE & Cucumis anguria $\mathrm{L}$. & $\mathrm{O}$ & - \\
\hline CYPERACEAE & $\begin{array}{l}\text { Cyperus sphacelatus Rottb. } \\
\text { Fimbristylis dichotoma }\end{array}$ & $\begin{array}{l}\mathrm{O} \\
\mathrm{O}\end{array}$ & $\overline{-}$ \\
\hline EUPHORBIACEAE & $\begin{array}{l}\text { Croton glandulosus L. } \\
\text { Phyllanthus niruri L. } \\
\text { Sebastiania corniculata }\end{array}$ & $\begin{array}{l}\mathrm{O} \\
\mathrm{O} \\
\mathrm{O}\end{array}$ & $\begin{array}{l}\mathrm{O} \\
- \\
-\end{array}$ \\
\hline FABACEAE & Stryphnodendron pulcherrimum & $\mathrm{O}$ & - \\
\hline LECYTHIDACEAE & $\begin{array}{l}\text { Eschweilera sp. } \\
\text { Lecythis lurida (Miers) }\end{array}$ & $\overline{-}$ & $\begin{array}{l}\mathrm{O} \\
\mathrm{O}\end{array}$ \\
\hline LOGANIACEAE & Strychnos sp. & - & $\mathrm{O}$ \\
\hline POACEAE & $\begin{array}{l}\text { Brachiaria brizantha } \\
\text { Digitaria ciliaris (Retz.) } \\
\text { Eragrostis ciliaris (L.) } \\
\text { Panicum laxum Sw. }\end{array}$ & $\begin{array}{l}\mathrm{O} \\
\mathrm{O} \\
\mathrm{O} \\
\mathrm{O}\end{array}$ & $\begin{array}{l}\mathrm{O} \\
- \\
\mathrm{O} \\
\mathrm{O}\end{array}$ \\
\hline RUBIACEAE & $\begin{array}{l}\text { Spermacoce verticillata (L.) } \\
\text { Spermacoce capitata }\end{array}$ & $\begin{array}{l}\mathrm{O} \\
-\end{array}$ & $\overline{\mathrm{O}}$ \\
\hline SOLANACEAE & $\begin{array}{l}\text { Physalis angulata } \mathrm{L} . \\
\text { Solanum juripeba Rich. }\end{array}$ & $\begin{array}{l}\mathrm{O} \\
\mathrm{O}\end{array}$ & $\overline{\mathrm{O}}$ \\
\hline VIOLACEAE & Hybanthus іресасиаnha (L.) & - & $\mathrm{O}$ \\
\hline
\end{tabular}

Nota: O: ocorrência de espécies aos 30 e 90 dias após a semeadura das leguminosas.

Tabela 2 - Infestação, diversidade e riqueza de plantas daninhas aos 30 e 90 dias após a semeadura das leguminosas de cobertura. Table 2 - Infestation, diversity and richness of weeds 30 and 90 days after sowing of cover legumes.

\begin{tabular}{|c|c|c|c|c|c|c|}
\hline \multirow[b]{2}{*}{ Tratamento } & \multicolumn{2}{|c|}{ Infestação (dias) } & \multicolumn{2}{|c|}{ Diversidade (dias) } & \multicolumn{2}{|c|}{ Riqueza (dias) } \\
\hline & 30 & 90 & 30 & 90 & 30 & 90 \\
\hline T1 (4x2 F.G.) & $59,00 \mathrm{ab}$ & $22,40 d$ & $1,38 \mathrm{c}$ & $1,35 a$ & $3,66 a$ & 3,33ab \\
\hline T3 (4x4 F.G.) & $63,33 a$ & $37,16 c$ & $1,45 \mathrm{bc}$ & $1,31 \mathrm{a}$ & $5,0 a$ & 4,33ab \\
\hline T5 (4X6 F.G.) & $67,33 a$ & $51,0 \mathrm{~b}$ & $1,55 a$ & $1,43 a$ & $6,33 a$ & $5,66 a$ \\
\hline T2 (4X2 F.P.) & 31,33b & $8,0 \mathrm{e}$ & $1,09 d$ & $1,04 \mathrm{a}$ & 3,33a & $2,66 b$ \\
\hline T4 (4X4 F.P.) & 43,33ab & $9,0 \mathrm{e}$ & $1,10 \mathrm{~d}$ & $1,08 \mathrm{a}$ & 4,33a & 3,33ab \\
\hline T6 (4X6 F.P.) & $52,66 a b$ & 9,0 e & $1,16 \mathrm{~d}$ & $1,14 \mathrm{a}$ & $5,0 \mathrm{a}$ & 4,66ab \\
\hline 4X4 (monocultivo) & 70,0a & $73,0 \mathrm{a}$ & $1,50 \mathrm{ab}$ & $1,56 a$ & $7,0 \mathrm{a}$ & 7,33a \\
\hline
\end{tabular}

Nota: Médias seguidas pela mesma letra não diferem pelo teste de Tukey a 5\%. F.G: feijão- guandu; F.P.: feijão-de-porco.

sobressaíram, contribuindo juntas com cerca de $58,4 \%$ da cobertura da comunidade infestante aos 90 dias.

Aos 90 dias, as espécies que apresentaram maior IVI na comunidade de plantas invasoras no cultivo de paricá foram: Spermacoce capitata, Eragrostis ciliaris, Brachiaria brizantha, Panicum laxum, Solanum juripeba, Memora magnifica e Hybanthus ipecacuanha. As espécies restantes apresentaram índices inferiores a 15\% (Tabela 3).

Apesar da alta abundância de espécies invasoras na fase inicial do experimento, observou-se que, em geral, o número de espécies invasoras diminuiu, ao 
Tabela 3 - Percentual dos parâmetros fitossociológicos apresentado pelas espécies de plantas daninhas amostradas aos 30 e 90 dias após a semeadura de leguminosas de cobertura em um plantio de Schizolobium amazonicum.

Table 3 - Percentage of phytosociological parameters presented by weed species sampled 30 and 90 days after sowing of cover legumes on a plantation of Schizolobium amazonicum.

\begin{tabular}{|c|c|c|c|c|c|c|c|c|}
\hline Espécie & & $30 \mathrm{D}$ & & & & $90 \mathrm{I}$ & & \\
\hline & DR & FR & DoR & IVI & DR & FR & DoR & IVI \\
\hline Spermacoce capitata & & & & & 30.86 & 25.53 & 20.14 & 76.53 \\
\hline Brachiaria brizantha & 22.12 & 26.62 & 25.88 & 74.63 & 9.88 & 14.89 & 18.27 & 43.04 \\
\hline Digitaria ciliaris (Retz.) & 13.27 & 16.23 & 15.85 & 45.35 & & & & \\
\hline Fimbristylis dichotoma & 11.95 & 9.74 & 10.48 & 32.16 & & & & \\
\hline Spermacoce verticillata & 12.39 & 9.09 & 8.10 & 29.58 & & & & \\
\hline Ipomoea sp. & 4.87 & 6.49 & 9.07 & 20.43 & & & & \\
\hline Lecythis lurida & & & & & 3.70 & 4.26 & 5.95 & 13.91 \\
\hline Physalis angulata L. & 2.65 & 3.90 & 2.46 & 9.02 & & & & \\
\hline Cyperus sphacelatus & 3.10 & 3.25 & 2.46 & 8.81 & & & & \\
\hline Eragrostis ciliaris (L.) & 1.77 & 2.60 & 2.46 & 6.83 & 18.52 & 10.64 & 19.97 & 49.12 \\
\hline Bidens pilosa L. & 1.77 & 2.60 & 2.11 & 6.48 & & & & \\
\hline Conyza sp. & & & & & 2.47 & 2.13 & 0.85 & 5.45 \\
\hline Croton glandulosus L. & 1.77 & 0.65 & 0.88 & 3.30 & 2.47 & 2.13 & 5.10 & 9.69 \\
\hline Eschweilera sp. & & & & & 2.47 & 2.13 & 0.85 & 5.45 \\
\hline Strychnos sp. & & & & & 1.23 & 2.13 & 1.70 & 5.06 \\
\hline Panicum laxum Sw. & 0.88 & 0.65 & 0.44 & 1.97 & 6.17 & 8.51 & 4.67 & 19.36 \\
\hline Sebastiania corniculata & 0.88 & 0.65 & 0.44 & 1.97 & & & & \\
\hline Cucumis anguria L. & 0.44 & 0.65 & 0.70 & 1.80 & & & & \\
\hline Solanum juripeba Rich. & 0.44 & 0.65 & 0.53 & 1.62 & 4.94 & 8.51 & 5.52 & 18.97 \\
\hline Memora magnifica & & & & & 4.94 & 6.38 & 7.22 & 18.54 \\
\hline Memora allamandiflora & 0.44 & 0.65 & 0.26 & 1.36 & 3.70 & 4.26 & 5.95 & 13.91 \\
\hline Phyllanthus niruri L. & 0.44 & 0.65 & 0.18 & 1.27 & & & & \\
\hline Stryphnodendron pulcherrimum & 0.44 & 0.65 & 0.18 & 1.27 & & & & \\
\hline Hybanthus ipecacuanha & & & & & 7.41 & 6.38 & 2.97 & 16.76 \\
\hline Morfotipo 1 & 17.70 & 12.34 & 15.40 & 45.44 & & & & \\
\hline Morfotipo 2 & 1.33 & 1.30 & 1.23 & 3.86 & & & & \\
\hline Morfotipo 3 & 1.33 & 0.65 & 0.88 & 2.86 & & & & \\
\hline Morfotipo 4 & & & & & 1.23 & 2.13 & 0.85 & 4.21 \\
\hline$\overline{\text { Total }}$ & 100 & 100 & 100 & 300 & 100 & 100 & 100 & 300 \\
\hline
\end{tabular}

Nota: DR: densidade relativa ; FR: frequência relativa ; DoR: dominância relativa ; IVI: Índice de Valor de Importância.

longo do período de avaliação, em decorrência da cobertura de leguminosas e do sombreamento do paricá em espaçamentos menores (Tabela 2).

\section{DISCUSSÃO}

A família Poaceae, provavelmente, foi favorecida pela alta temperatura, intensa radiação solar predominante na área de estudo e pela sua maior eficiência na exploração dos fatores de produção do solo (SOUSA et al., 2003).

Ao se comparar a composição florística aos 30 e aos 90 dias após a semeadura das espécies leguminosas, observa-se que várias espécies, como Bidens pilosa, Ipomoea sp., Cucumis anguria, Cyperus sphacelatus, Fimbristylis dichotoma, Phyllanthus niruri, Sebastiania corniculata, Stryphnodendron pulcherrimum, Digitaria ciliaris, Spermacoce verticillata e Physalis angulata ,não foram encontradas na avaliação realizada aos 90 dias. A ausência dessas espécies foi ocasionada, provavelmente, pela cobertura proporcionada pelas leguminosas, o que dificultou a passagem de radiação solar até o solo, fazendo com que os propágulos contidos no banco de sementes não germinassem.

O fato de o feijão-de-porco ter apresentado maior eficiência na redução do número de espécies de ervas daninhas pode ser explicado pelo seu sistema radicular denso e profundo, seu rápido crescimento e sua capacidade de produzir grande quantidade de biomassa para cobrir toda a superfície do solo (LOPES, 2000).

Estudos realizados com espécies do gênero botânico Canavalia constataram que estas espécies apresentaram alta capacidade de absorção de água e nutrientes em

Revista Árvore, Viçosa-MG, v.35, n.3, p.391-399, 2011 
maiores profundidades, ampliando a exploração do solo (ALVARENGA et al., 1995) devido ao sistema radicular profundo. A alta capacidade de produção radicular das espécies do gênero Canavalia é uma característica importante para o controle das plantas daninhas em plantações florestais (SILVA et al., 2002).

Estudos realizados por Heinrichs et al.(2005) mostraram que a espécie $C$. ensiformis apresentou maior produção de fitomassa e acúmulo de nutrientes quando comparada às leguminosas de cobertura, como Mucuna deeringiana, C. cajan e Crotalaria spectabilis. No entanto, devido à agressividade de crescimento dessa leguminosa, aos 60 dias encontra-se em estado vegetativo bem desenvolvido e com alta demanda por fatores de crescimento. Dessa forma, o feijãode-porco torna-se prejudicial a outras culturas, pois a competição por fatores de crescimento (água e nutrientes) deverá dificultar ainda mais as culturas de interesse.

Verificou-se, na área de estudo, que o monocultivo de paricá (4m x $4 \mathrm{~m}$ ) apresentou alto percentual de infestação de plantas daninhas quando comparado aos tratamentos que continham as leguminosas de cobertura. Do mesmo modo, os tratamentos com a leguminosa feijão-guandu (C. cajan) apresentaram valores de infestação elevados aos 30 e 90 dias, quando comparados aos tratamentos com feijão-de-porco. Isso ocorreu, provavelmente, devido à arquitetura e ao porte ereto dessa leguminosa, que propiciam melhores condições para a proliferação de invasoras. Outra explicação para este resultado é dada por Fávero (2001), que atribui esse resultado e esse comportamento ao crescimento inicial lento do guandu, o que contribui para a infestação de invasoras.

Aos 30 dias, a diversidade de espécies invasoras das áreas onde o paricá foi cultivado no espaçamento $4 \mathrm{~m} \times 6 \mathrm{~m}$, consorciado ao feijão-guandu, não diferiu das áreas de monocultivo, com espaçamento 4m x 4m. Esse resultado pode ser explicado pelos espaçamentos utilizados serem mais amplos, acarretando maior exposição do solo à incidência de raios solares, favorecendo o surgimento de plantas invasoras. Porém, apesar do crescimento mais lento e hábito arbustivo, o feijão-guandu possui um sistema radicular profundo, tornando-o capaz de resistir ao estresse hídrico e romper as camadas adensadas do solo (NENE; SHEILA, 1990). Além disso, esse feijão possui potencialidades alelopáticas. Teixeira et al. (2004) constataram que essa leguminosa apresentou efeito alelopático sobre o picão-preto (Bidens pilosa).

A alta frequência da espécie da família Poaceae pode ser explicada pela sua maior eficiência na exploração dos fatores de produção do solo (SOUSA et al., 2003).

A espécie Croton glandulosus não se destacou também em termos de abundância no levantamento de plantas invasoras, realizado por Brighenti et al. (2003), no cultivo de girassol.

As espécies Spermacoce capitata e Brachiaria brizantha foram muito frequentes na área estudada, o que é preocupante, pois espécies dos gêneros Brachiaria e Spermacoce interferem significativamente no crescimento inicial de essências florestais, como em mudas de Eucalyptus grandis (BEZUTTE et al., 1995; COSTA, 1999).

A maioria das áreas destinadas a reflorestamento tem englobado áreas antes ocupadas por pastagens, com predominância das espécies do gênero Brachiaria e Panicum. Portanto, essas espécies tornam-se problemáticas em áreas de reflorestamento, principalmente devido às suas características, como elevada agressividade, intensa capacidade de produção e longevidade de sementes (COSTA et al., 2002).

Cantarelli et al. (2006) observaram que a interferência imposta pelas plantas daninhas à cultura de Pinus taeda é mais severa principalmente na fase inicial de crescimento, ou seja, do transplante até cerca de 1 ano de idade.

A diminuição da infestação, ao longo do período de avaliação, em decorrência da cobertura de leguminosas e do sombreamento do paricá, quando cultivado em espaçamentos menores, evidencia que técnicas relativamente simples de tratos silviculturais aliadas à adoção de leguminosas podem contribuir, de maneira eficaz, para o controle e manejo de plantas invasoras, a diminuição do uso de agrotóxicos e consequentemente a redução dos custos de manutenção de reflorestamentos e a melhoria da qualidade ambiental.

\section{CONCLUSÕES}

O uso de espaçamentos amplos entre plantas de paricá contribuiu para maior diversidade e riqueza de plantas invasoras. A maior infestação foi observada no monocultivo de paricá, e a menor no consórcio 4m x 2 m com feijão-de-porco.

Revista Árvore, Viçosa-MG, v.35, n.3, p.391-399, 2011 
A semeadura de leguminosas de cobertura entre as plantas de paricá limitou o crescimento de espécies invasoras. As menores infestações foram observadas nas combinações que continham feijão-de-porco (Canavalia ensiformis).

A semeadura de leguminosas de cobertura entre plantas de paricá apresentando diferentes espaçamentos afeta a composição florística das comunidades de plantas invasoras.

\section{AGRADECIMENTOS}

Os autores expressam seus agradecimentos ao Engenheiro Florestal Mauro Carvalho, funcionário da PAMPAEXPORTAÇÕES LTDA, pela atenção, dedicação e ajuda prestada ao longo da coleta de dados deste trabalho, e aos taxonomistas M. Sc. Elielson Rocha e a M.Sc. Silvane Rodrigues, pela identificação do material botânico.

\section{REFERÊNCIAS}

ALVARENGA, R. C. et al. Características de adubos verdes de interesse para a conservação e recuperação de solos. Pesquisa

Agropecuária Brasileira, v.20, n.1, p.175-185, 1995.

ANDRADE, M. J. B.; RAMALHO, M. A. P. Cultura do feijoeiro. Lavras: Universidade Federal de Lavras, 1995. 97p. (Apostila).

AYRES, M. et al. BioEstat 3.0: aplicações estatísticas nas áreas das ciências biológicas e médicas. Belém: Sociedade Civil; Brasília: CNPq, 2003. 290p.

BEZUTTE, A. J. et al. Efeito de períodos de convivência de Brachiaria decubens, no crescimento inicial de Eucalyptus grandis e seus reflexos na produtividade da cultura aos três anos de idade. In: CONGRESSO BRASILEIRO DA CIÊNCIA DAS PLANTAS DANINHAS, 20, Florianópolis, 1995. Anais... Florianópolis: 1995. p.250-251.

BRIGHENTI, A. M. et al. Cadastramento fitossociológico de plantas daninhas na cultura de girassol. Pesquisa Agropecuária Brasileira, v.38, n.5, p.651-657, 2003.
CANTARELLI, E. B. et al. Efeito do manejo de plantas daninhas no desenvolvimento inicial de Pinus taeda em várzeas na Argentina. Revista Árvore, v.30, n.5, p.711-718, 2006.

CARVALHO, E. P.; TORRES, L. G. Manejo de lãs malas hierbas en sistemas agroforestales de Amazônia. Agroforesteria en las Américas, v.3, p.6-9, 1994.

COSTA, A. G. F. Efeito da densidade de plantas de Spermacoce Iatifólia Aubl. e de Commelina benghalensis L. sobre o crescimento inicial de Eucalyptus grandis W. Hill ex Maiden. 1999. 56f. Monografia (Graduação em Agronomia) - Faculdade de Ciências Agrárias e Veterinárias. Universidade Estadual Paulista Júlio de Mesquita Filho, Jaboticabal, 1999.

COSTA, E. A. D. et al. Eficiência de nova formulação do herbicida oxyfluorfen no controle de plantas daninhas em área de Pinus caribea Morelet var. hondurensis Barr. et Golf. Revista Árvore, v.26, n.6, p.683-689, 2002.

DIAS-FILHO, M. B. Plantas invasoras em pastagens cultivadas da Amazônia: estratégias de manejo e controle. Belém: EMBRAPA-CPATU, 1990. 103p. (Documentos, 52)

EMPRESA BRASILEIRA DE PESQUISA AGROPECUÁRIA - EMBRAPA. Feijão guandú. Disponível em: <http:// www.cnpgc.embrapa.br/publicações/ct/ct13/ 02guandú.html\#2.1. Acesso em: 13 de Jul de 2004.

FÁVERO, C. et al. Modificações na população de plantas espontâneas na presença de adubos verdes. Pesquisa Agropecuária

Brasileira, v.36, n.11, p.1335-1362, 2001.

HEINRICHS, R. et al. Características químicas de solo rendimento de fitomassa de adubos verdes e de grãos de milho, decorrente do cultivo consorciado. Revista Brasileira de Ciência do Solo, v.29, n.1, p.71-79, 2005.

LOPES, O. M. N. L. Feijão-de-porco: Leguminosa para adubação verde e cobertura de solo. Acre: Embrapa Amazônia Oriental, 1998. p.1-4. (Recomendações Básicas, 37). 
LOPES, O. M. N. L. Feijão-de porco:

Leguminosa para controle de mato e adubação verde do solo. Belém: Embrapa-CPATU, 2000. 4p. (Embrapa-CPATU. Recomendações técnicas, 12).

LUDWING, J. A.; REYNOLDS, J. F. Statiscal ecology: a primer on methods and computing. New York: John Wiley \& Sons, 1988. 337p.

MULLER-DOMBOIS, D.; ELLENBERG, H. Aims and methods of vegetation ecology. New York: Jhon Wiley \& Sons, 1974. 574p.

NENE, Y. L; SHEILA, V. K. Pigeonpea: geography and importance. In: NENE, Y. L.; HALL, S. D.; SHEILA, V. K. (Eds.). The Pigeonpea. Cambridge: CAB International/ ICRISAT, 1990. p.1-14.
SILVA, J. A. M. et al. Caracterização de sistemas radiculares de leguminosas cultivadas sob irrigação no Vale do São Francisco: 1. Padrão e distribuição. In: REUNIÃO BRASILEIRA DE MANEJO E CONSERVAÇÃO DO SOLO E DA ÁGUA, 14., 2002, Cuiabá. Anais... Cuiabá: SBCS/UFMT-DSER, 2002. CD ROM.

SOUSA, G. F. et al. Plantas invasoras em sistemas agroflorestais com cupuaçuzeiro no município de Presidente Figueiredo (Amazonas, Brasil). Acta Amazônica, v. 33, n.3, p. 353-370, 2003.

TEIXEIRA, C. M.; ARAÚJO, J. B. S.; CARVALHO, G. J. Potencial alelopático de plantas de cobertura no controle de picão-preto (Bidens pilosa L.). Ciência e Agrotecnologia, v. 28, n. 3, p. 691-695, 2004. 